\title{
Multimedia Teaching Research on Vehicle Body Structure
}

\author{
Yanfeng Xing* \\ Automotive Engineering College \\ Shanghai University of Science Engineering \\ Shanghai, China
}

\author{
Xiaoli Wei \\ Library \\ Shanghai University of Science Engineering \\ Shanghai, China
}

\begin{abstract}
The knowledge capacity can be effectively increased through applying the multimedia teaching for vehicle body structure. The structure and theory of body components are revealed by combining images and videos, which cooperate with blackboard writing to improve students' learning interest and deeply understand teaching content. Students are easy to learn and motivate creative thinking, which can improve cognitive ability and thinking ability through multimedia teaching.
\end{abstract}

Keywords-vehicle body structure; multimedia; creative thinking; courseware

The vehicle body structure is one of the professional foundation courses of automotive engineering institute majoring in vehicle engineering, as well as special technology after graduated. There are 32 class teaching hours for this course. The teaching contents include the history of body development, the classification of body structure, doors, chairs, etc., which are difficult to describe with oral and blackboard writing due to a large number of mechanical mechanism and its working principle. The problems of the content of teaching structure and its principle, which is difficult to explain, can be resolved effectively via multimedia teaching. It can also get better teaching results in this way.

The main trend of the development of education in modern engineering is to cultivate students' ability from the emphasis on teacher education to student learning. The education certification mainly emphasizes the cultivation of students' abilities, such as active learning ability, self-learning ability, active practice ability, team work ability, communication and communication skills, etc. For Chinese engineering education universal standard according to the Washington agreement, carry out the evaluation of "people-oriented" concept, to develop students, training objectives, graduation requirements, continuous improvement, course system, teaching staff, support conditions, such as seven criteria, "student-centered" throughout the whole process of the students from the entry exit. Based on the results of OBE (Outcomes -based Education), the Education certification concept has greatly impacted the traditional curriculum oriented engineering Education concept in China. Therefore it is very important to improve classroom teaching.

\section{THE ADVANTAGES AND DISADVANTAGES OF MULTIMEDIA COURSEWARE}

Currently, multimedia courseware has been widely applied to various courses, both class structure and theory class, most of them is multimedia teaching. Although it has its own advantages like good visibility, it does not completely replace the blackboard. Both ways need to be closely integrated to achieve the best teaching results.

The research of computer assisted instruction was firstly proposed by America from 60s of last century [1]. The famous evaluation organization (Micro SIFT) evaluated courseware in three aspects, which include content, teaching and character and technique character [2]. Multimedia teaching evaluation system can improve combination of current education theory and education practice [3 4]. Ping proposed pondering and countermeasures for the transformation of teaching modes assisted by multimedia technology aiming to improve the education and teaching quality of college teachers [5]. The application and integration of multi-agent technology in university classroom were discussed by Huang [6]. Zhang explored the schedule of and approaches to applying multimedia technology to translation teaching, based on the principles and tasks of translation teaching. Statistics and contrastive studies between the multi-media teaching and traditional teaching of translation [7].

Multimedia courseware is helpful in the main classroom teaching. Generally produced by Microsoft's PowerPoint software, you can also make other software assisted, such as Authorware, Director, Flash and other software Founder Author. Courseware can reduce the time of classroom blackboard, wall charts and blackboard drawing. As a result, it can effectively improve teaching efficiency and increase knowledge capacity. During the course of teaching the history of body development, image teaching can increase students' knowledge with the car pictures from carriage to wedge in different periods. Images can also be replaced by charts. When teacher explains power seats, the use of animation video allows students to better understand the process and principle of electric seat position change. Video teaching can improve students' perceptions with its rich, vivid and visual content, which is conducive to attracting the attention of students. It should be difficult to achieve the same effect using a traditional teaching. 
Multimedia cannot substitute for teacher however. Improper use of teaching courseware will result in the decrease of teaching efficiency and effect. Take the basic computer course as an example. When the college student is taught by multimedia, if teachers do not explain the content, relying solely on video lectures, he may not grasp the knowledge. The quality of teaching is so poor that even many students cannot pass the exam. Nevertheless, traditional blackboard teaching can overcome the difficulty focusing on performance and formula deduction of multimedia. Writing on the blackboard is not only helpful to classroom interaction, but also provides much convenience. Teachers can do additions and deletions easily and write according to their need to make up for the lack of courseware content. For instance, when explaining the case that inner cover parts require precise assembly dimensions, the teacher can explain the different requirements on the inner and outer cover by drawing on the blackboard. They can combine with the knowledge of mechanics of materials to make students have a good knowledge of it, and deepen the interpretation of this key content as well.

Although multimedia plays an important role in the teaching process, teacher still in a dominant position. Students are the main body of learning. No matter how wonderful and detailed, courseware cannot replace teacher's explanations, especially for the principles of the content. Some knowledge and concepts of the body structure can be literal, such as the radiator mask, its role is to protect the radiator and decorate styling feature. So the curriculum of body structure is easier to learn. But others need detailed interpretation, such as the principle of the expansion valve of the air conditioning system. It is difficult to understand just relying on a video presentation, so teachers need to use the blackboard to explain step by step. Teachers are the organization managers of class. Some students recite words for their CET and other students play video games while teachers speak in class is very lively and fascinating, so teachers' constraints and management are needed in the teaching process. These will be difficult just depending on multimedia. Teachers should design reasonable issues to promote interaction between students, and guide students to play the main role of students via multimedia courseware during the teaching process.

\section{Multimedia Courseware Produce}

The positioning refers to the course in the curriculum system, according to the course content, credits, object-oriented analysis to study this course students have the knowledge and ability, its content and the request from the support of graduation requirements and training objectives. Therefore, the positioning of automobile body structure should be as follows:

(1) This course is located in the specialized course group of the automotive engineering college, which is an elective course for vehicle engineering majors, which is opened in the fifth and sixth term. The course through the interpretation of the body and each subassembly, chairs, the structure characteristics of air conditioning and other components, parts function, to his request, let the vehicle engineering students to master and understand body structure, for its design, manufacture to lay the good foundation.
(2) This course takes the vehicle engineering major as the main body, radiating machinery manufacturing and automation (automotive engineering).

(3) Through the study of this course, it makes students understand the role of main parts in the body, functions and the requirements for training students' ability to solve complex engineering problems, and for the production process design, product testing and quality control to provide knowledge reserves.

In the manufacturing process, we should focus on the quality of multimedia courseware. Excellent multimedia courseware can grab students' attention, but inferiors make students disgusted and is difficult to show the advantages of it. So we need to pay attention to the interface, content and plate design of courseware.

Courseware interface should be generous appearance and uniform style, as well as the programming interface. The interface design is an important part of courseware. The unified style courseware can be focused easily by students. In the body structure course, there are a lot of different levels of the title. If the title of the level is not displayed, it is not easy for students to grab outline. If each courseware shows the affiliation of different titles, there must be more repeated content but less useful information, so it needs flexibility. Mark topmost title on the title of each page. It can help the students know the membership of the part. But its content is arranged according to the different level. This can mostly use the space of courseware. However, interface design should not be too fancy. It is easy to disperse the students' attention, especially excessive custom animations (such as flying into, cut, blinds, stressed, etc.) are easy to make students bored and waste lots of teaching time. But the key elements, especially the interactive content, can apply the appropriate custom animation. Explain the following content by asking questions instead of showing the content, and then the teaching effect will be better. The interface color is also important elements. White or other light color dominated the background. If the color is red, students will soon be drowsy. Try to make the text color contrast with background color. For example, white font on a black background, yellow background dark blue font, etc. However, the size of the font should be paid attention to, general title need 36 words or so. The minimum font of text should not be less than 20 words. By the title level may in turn increase the size, so as to the students sitting in the hind can see the course. Unless special emphasized, the size should not be too large, otherwise the contents of each page will be too little.

The main contents of the car body structure courseware involve body model, body classification, body structure, front and rear panels, body cockpit, principle of air conditioning structural, seats, doors and safety devices and other parts, which includes not only the various parts of the body shape, the structure, function, but also need to analyze the operation of bodies, such as air conditioning systems, seat adjustment systems and airbag systems, etc. The courseware has abundant content, and the production quantity is very large. It is extremely difficult to display various structural principles. Therefore, the following steps can be adopted. The figure 1 shows the flowchart of multimedia courseware. 
1) Analyzing the outline, clearing the type of courseware interface, selecting Slide Style, determining the layout of text and images, trying to make the style of interface introduction clear and consistent.

2) Filling the main text according to the design of different chapters' cover and catalogue.

3) Adding charts according to demand and adjusting its layout based on the content of the slide to make it simple and nice.

4) Those parts of complex shape can be displayed by a plurality of angle images. If there is a video, use the video display.

5) For the principle of mechanism, we can add notes to explain by searching for the relevant video principle via Baidu, Google and other search engines.

6) For those videos, which are unable to download from the Internet or do by yourself (such as the use Flush etc.), we establish video files by using screen recording software.

7) Arranging all of the images, videos, flash and other files reasonably to achieve better teaching results.

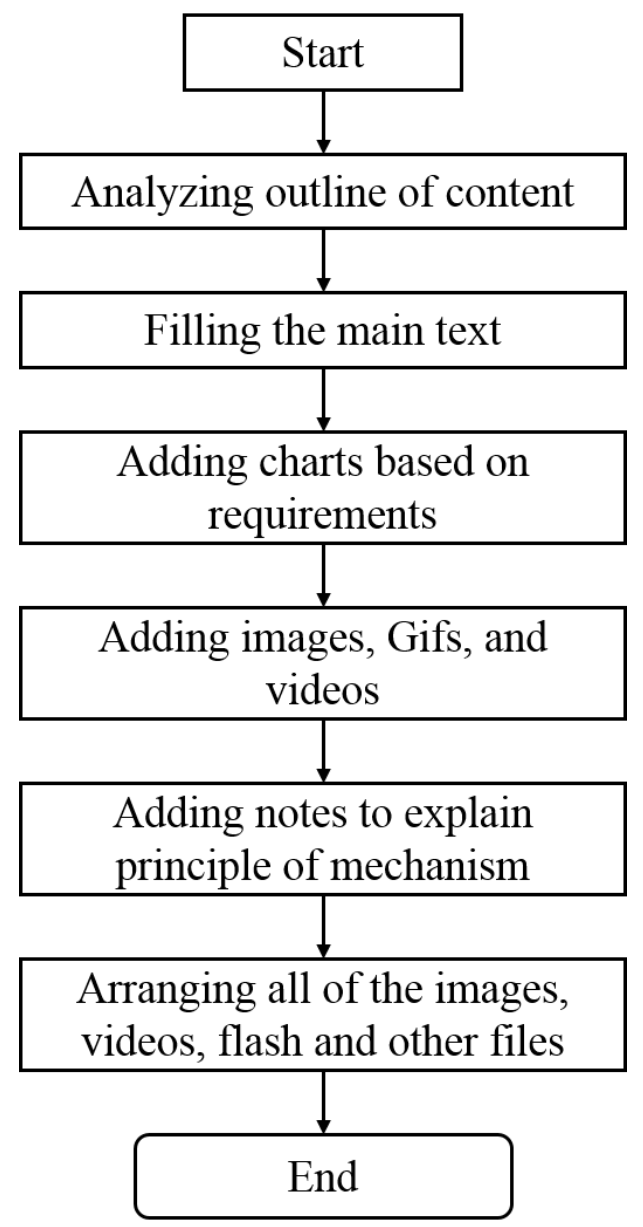

Fig. 1. Flowchart of multimedia courseware

\section{THE MULTIMEDIA TEACHING}

Multimedia teaching methods are based on courseware, but it does not instill knowledge to students, which requires teachers to play a leading role to mobilize the enthusiasm of students and enable them to take the initiative to learn.

Now, “excellence engineers” education is emphasized. It is to make the students see the knowledge of factory producing and processing and unite the theory with the actual production on the basis of class. Short videos or pictures are used to show the factory processing process. It enables students to recall the learning content production environment. Students' interest increases in learning at the same time. For example, many students majored in mechanical engineering lack of the knowledge of assembly. They can increase recognition through the way of asking questions based on video display. In the process of BMW automobile, body parts form by stamping. All those classmates who ask questions know it's hydraulic punch, but few students know the advantages and disadvantages of hydraulic, so we can analyze the characteristic of hydraulic motion through the video of simulative process.

In the process of teaching, although based on the sequence of courseware, we should also be flexible, neither just read or recite the courseware nor just let students watch the video without discussion. In addition, the courseware should be reorganized based on the case of students. Some students are more familiar with part of the structure. Teachers should speak less or focus on analyzing the working principle. In the process of play animation or movie, lots of information will produce. For some critical information, although not important, it can be explained appropriately to broaden students' horizon. For example, in the video of the body process, there will be many scenarios of automatic welding robot. To ask questions like how flexible robots do sports can raise student's interest. The answer is probably not quite right, then you can explain lots of these robots are planned their paths through the "Teach" mode, and then explain the advantages and disadvantages of such a robot series and parallel robots. It can increase students' knowledge and cultivate their creativity thinking.

In the teaching process, teachers should not only follow the courseware but also create active classroom atmosphere by asking questions and other means. For students sleeping or playing games, teacher should timely remind them to listen carefully. However, few students can always concentrate on the class during 90 minutes of the lecture, so students should be allowed a few minutes of desertion, especially when talking about non-priority content. Teachers should pay attention to the response of students during the lecture. If all of them are wondering, some interesting body structure content should be explained to attract their attention. For students who don't listen to the teacher carefully, asking questions is a good way to arouse their learning ability.

\section{CONCLUSION}

In this paper, we have studied multimedia teaching methods about the car body structure. First, the advantages and disadvantages of multimedia courseware are analyzed. Then, the multimedia status in the teaching process is discussed. Next, the interface form and style of multimedia are introduced, and 
the production process is also set up. Finally, the possible issues and the corresponding strategies are put forward.

\section{REFERENCES}

[1] J. Dai, "Research on efficiency of multimedia-assisted instruction abroad", Comparative Education Review, vol. 26, no. 8, pp. 77-80, 2005 (In Chinese)

[2] Y. Wang, Z. Zhong, "The theoretical model, criterion and method in evaluating multimedia courseware in classroom (MCC) and its Instruction effect”, Modern Education Technology, vol. 14, no. 1, pp. 56-62, 2004. (In Chinese)

[3] L. Anderson, "International encyclopedia of teaching and teacher education”, Progamon Press, 1995.
[4] D. Zhao, "Multimedia technology and college classroom teaching modernization”, Computer CD Software and Applications, pp. 90,92, 2013. (In Chinese)

[5] R. Ping, "An analysis on the transformation of teaching modes assisted by multimedia technology", Journal of Henan Polytechnic University (Social Sciences), vol. 18, no. 2, pp. 110-113, 2017. (In Chinese)

[6] K., Huang, "Multimedia technology and college classroom teaching modernization”, Journal of henan Science and Technology, no. 10, pp. 278,281, 2013. (In Chinese)

[7] H. Zhang, "Multimedia assisted English translation teaching practice exploration”, Foreign Languages and Their Teaching, no. 12, pp. 38-41, 2007. (In Chinese). 